\title{
Thermal and non-Thermal Effects of Humidity on Comfort
}

\author{
Larry Berglund \\ Graduate School of Tohoku University, Japan \\ (received 25 September 1997; accepted 7 November 1997)
}

\begin{abstract}
Humidity affects comfort in a number of ways both directly and indirectly. It is a factor in our energy balance, thermal sensation, skin moisture, discomfort, sensation of fabrics, health and perception of air quality. Reduced humidity in summer makes us feel cooler at the same temperature, our skin feels drier and less sticky, fabrics and clothing feel smoother and more pleasant to our touch and the air is perceived to be fresher. Much of the discomfort related to higher humidities appears to be due the higher levels of skin moisture, thus increased air speed alone is often effective in such environments. Further, the comfort and related benefits perceived by occupants and customers from humidity reduction may encourage and justify the design and implementation of HVAC systems with increased dehumidification capabilities such as Cold Air /Ice Storage systems.
\end{abstract}

Key words: humidity, comfort, skin moisture, clothing, perceived air quality

\section{Introduction}

Humidity affects us both thermally and non-thermally. It is a factor in our energy balance, thermal sensation, skin moisture, discomfort, tactile sensation of fabrics, health and perception of air quality. In 1966, ASHRAE Standard 55 "Thermal environmental conditions for human occupancy" introduced a definition for thermal comfort which has become widely used and quoted [1]. The definition: "Thermal Comfort is that condition of mind that expresses satisfaction with the thermal environment." The definition implies that the judgment of comfort is a cognitive process that may involve many inputs and is the result of physical, physiological and psychological processes.

A possible model of how the conscious mind may reach conclusions about thermal comfort and discomfort is illustrated in the schematic of Figure 1. The schematic suggests that in addition to direct thermal sensation, the effort of regulating body temperature also affects our perceptions of comfort. Skin and internal temperatures, skin moisture and physiological processes all contribute to our state of satisfaction according to Figure 1. Thus comfort seems to occur when body temperatures are maintained with the minimum of physiological regulatory effort. The schematic also shows how conscious behavioral actions by the person to improve comfort are related to sensation and discomfort.

The role of regulatory effort and body temperatures in comfort is highlighted by experiments of Chatonnet and Cabanac [3] and observations of Kuno et al.[4]. In Chatonnet's experiments the sensation of placing the hand for 30 seconds in relatively hot or cold water $\left(30-38{ }^{\circ} \mathrm{C}\right)$ were compared with the person at different thermal states. When the person was over-heated or hyperthermic the cold water was pleasant but the hot water was very 
unpleasant. When in a cold or hypothermic state the hand felt pleasant in hot water and unpleasant in cold water. Kuno describes similar observations during transient whole body exposures to hot and cold environments. When in a state of thermal discomfort any move away from the thermal stress of the uncomfortable environment is perceived as pleasant during the transition.

\section{Thermal Sensation}

A good correlate with thermal comfort is thermal sensation [5]. The word and numerical scale commonly used to categorize or label thermal sensation is listed in Table 1. Thermal comfort is generally associated with a neutral or near neutral whole body thermal sensation. Thermal sensation depends on body temperatures which depend on thermal balance and the effects of environmental factors (temperature, radiation, air motion and humidity) and personal factors ( metabolism or activity and clothing) $[6,7]$.

\section{Thermal Balance}

The energy flow and heat storage elements of the human energy balance can be expressed as:

$$
S=M-W-\text { Ers - Edif - Res }-R-C-K
$$

where $S=$ rate of body heat storage, $M=$ metabolic energy production, $W=$ mechanical

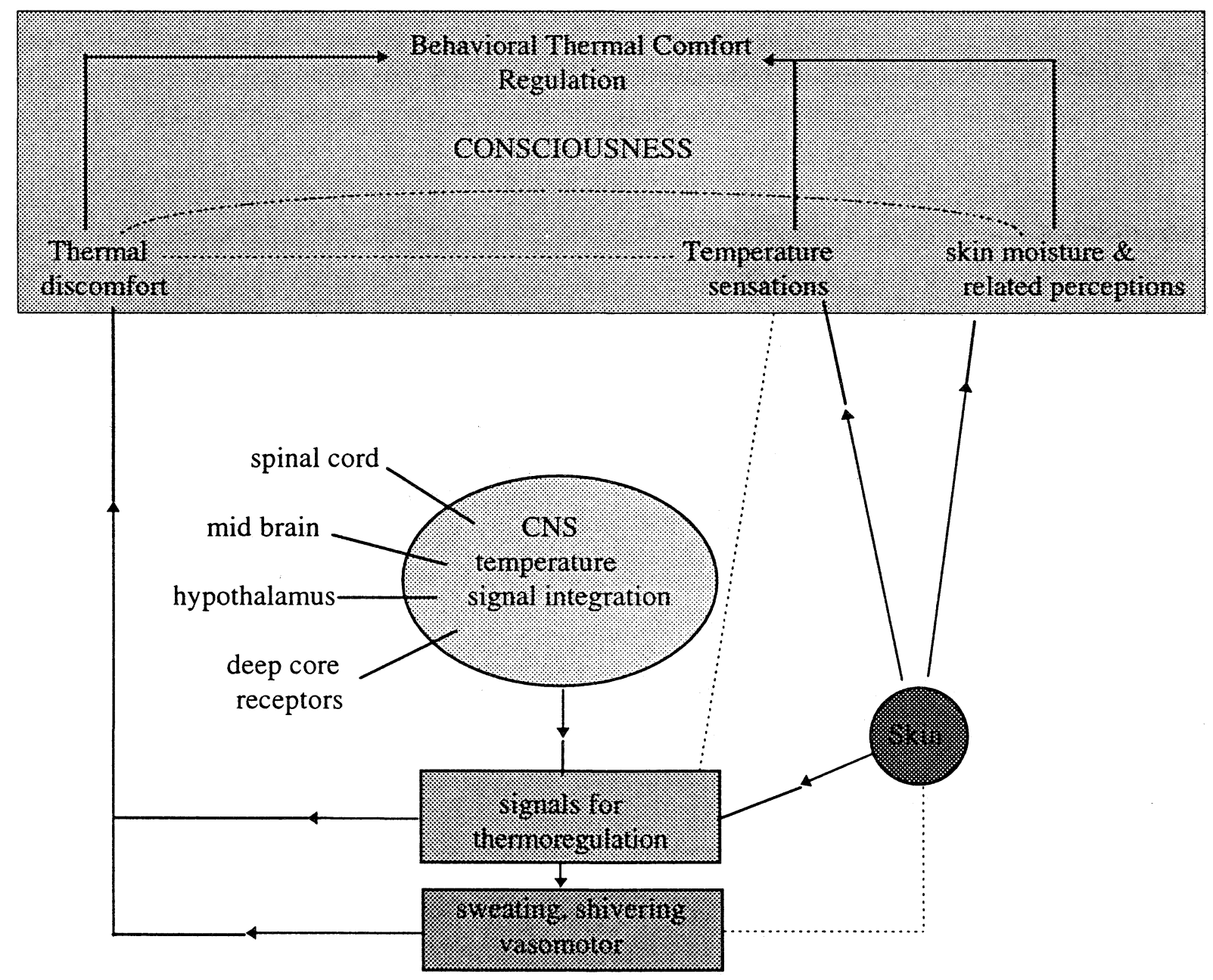

Figure 1. Schematic representation of comfort and related sensations [modified from Hardy(2)]. Solid lines refer to information channels and dashed lines to interactions. 
Table 1. Category scale and numerical code for thermal sensation and thermal comfort

$\begin{array}{rc}\text { Thermal sensation } & \text { numerical code } \\ \text { very hot } & +4 \\ \text { hot } & +3 \\ \text { warm } & +2 \\ \text { slightly warm } & +1 \\ \text { neutral } & 0 \\ \text { slightly cool } & -1 \\ \text { cool } & -2 \\ \text { cold } & -3 \\ \text { very cold } & -4\end{array}$

work, Ers = heat loss by regulatory sweating, Edif = heat loss from water diffusing through the skin, $R e s=$ respiratory heat loss, $R=$ radiative heat loss, $C=$ convective heat loss to air, and $K=$ conductive heat losses. Human autonomic thermoregulatory processes adjust skin blood flow and sweating to maintain stable body temperature and eliminate long duration rates of heat storage $(S=0)$. Humidity affects the evaporation of water from the respiratory mucous (Res) and sweating surfaces (Ers) and its diffusion through the skin (Edif). In turn, evaporation affects the energy balance $(S)$ and thereby body temperatures and thermal sensations. When evaporation processes of the skin are compromised or enhanced, skin temperatures change and this then is directly sensed by the temperature sensors of the skin. Though, sedentary persons depend much less on perspiration for thermal balance than when at higher activity levels, humidity still has a significant direct thermal effect.

The rate of water loss depends largely on vapor pressure differences between the body and its surrounding air. An adult resting in a $24^{\circ} \mathrm{C} 50 \%$ relative humidity environment and wearing trousers and a long sleeved shirt ( 0.6 clo) losses about 32 grams per hour of water to the environment. Of these $12 \mathrm{~g} / \mathrm{h}$ are from the nose and respiratory surfaces and the remaining $20 \mathrm{~g} / \mathrm{h}$ is lost from water diffusing through dry non-sweating skin. In terms of energy, these evaporative losses (Res + Edif)
Thermal comfort numerical code

$\begin{array}{rr}\text { intolerable } & 4 \\ \text { very uncomfortable } & 3 \\ \text { uncomfortable } & 2 \\ \text { slightly uncomfortable } & 1 \\ \text { comfortable } & 0\end{array}$

represent 21 watts or $20 \%$ of the person's total heat loss. The metabolism of an average resting adult is about 105 watts and since the resting person performs no thermodynamically useful work (lifting a weight etc., $W=0$ ), all of the metabolic energy ends up as heat that must be to be dissipated to the environment. For this example with 21 watts of waste heat carried to the environment by water vapor flow, the remaining 84 watts are transferred by the dry heat transfer mechanisms of convection, radiation and conduction.

Decreasing the relative humidity of the $24^{\circ} \mathrm{C}$ environment from 50 to $20 \%$ increases the evaporation rate to $38 \mathrm{~g} / \mathrm{h}$ and the associated energy loss to 26 watts or to $25 \%$ of the example person's total 105 watt energy loss. This increased passive evaporation decreases the needed dry heat transfer for energy balance to 79 watts. Further, it results in a slight lowering of the skin's temperature by $0.3{ }^{\circ} \mathrm{C}$ to about $32.9{ }^{\circ} \mathrm{C}$. As a result the person feels a little cooler in the drier $20 \%$ $\mathrm{RH}$ environment than in the $50 \% \mathrm{RH}$ one at the same temperature. For the person in the $20 \%$ RH environment to have the same skin temperature and feeling of warmth as in the $24^{\circ} \mathrm{C} 50 \% \mathrm{RH}$ setting the temperature would need to increase about $1{ }^{\circ} \mathrm{C}$ to $25^{\circ} \mathrm{C}$.

In warmer conditions or with increased activity and metabolism, active perspiration is required for thermal balance and the effect 
of humidity is greater. Metabolism is often characterized with the dimensionless Met unit: the ratio of actual to resting metabolism. A resting person with this system has a metabolism of 1 met. In the example above, if the person were continuously walking in the $24{ }^{\circ} \mathrm{C} 50 \% \mathrm{RH}$ environment the person's metabolism would be about 3 times higher( 3 met) or 315 watts. The convective and radiative loses would change little as would the water diffusion $(20 \mathrm{~g} / \mathrm{h})$. The respiratory heat loss would increase 3 times $(36 \mathrm{~g} / \mathrm{h})$ in proportion to metabolism and breathing. However active perspiration which was absent in the resting case would now be about $240 \mathrm{~g} /$ $\mathrm{h}$ and its evaporation would carry away body heat at the 161 watt rate

\section{Acceptability}

The ASHRAE comfort standard specifies the environmental conditions necessary for a neutral thermal sensation and also gives a range of parameter values that are expected to provide an environment that is thermally acceptable to at least $80 \%$ of the occupants. In terms of temperature, ASHRAE Standard 55-92 [8] specifies a band of temperatures about $3.5^{\circ} \mathrm{C}$ wide.

As shown by Fishman [9] and others [10], the clothing worn by occupants is influenced by the season and outside weather. Clothing worn indoors in summer is generally of lighter weight with a lower insulating value than that worn in the winter. The clothing worn in North America is about 0.5 clo in summer (thin trousers and short sleeved shirt) and about 0.9 clo in winter (heavier trousers with long sleeved shirt and sweater or business suit). The clo unit is a widely used and convenient measure of thermal resistance: 1 clo $=0.155 \mathrm{~m}^{2} \mathrm{~K} / \mathrm{W}$. A heavy two piece business suit with accessories has an insulation value of about 1 clo while a pair of shorts is about 0.05 clo. The thermally acceptable temperature range for indoor winter clothing is between effective temperatures of 20 and $23.5^{\circ} \mathrm{C} \mathrm{ET*}$. For summer clothing the range is between 23 and $26^{\circ} \mathrm{C} \mathrm{ET*}$.

At the temperature boundaries of the comfort zone an average person may have thermal sensations of approximately +.5 at the warm side and -.5 at the cooler ET* boarder. By definition $\mathrm{ET}^{*}$ is the temperature at $50 \%$ relative humidity that will transfer the heat to the environment at the same rate with the same skin temperature and skin wettedness as in the actual temperature and humidity. Skin wettedness [11] is a measure of skin moisture and is the fraction of skin covered with perspiration necessary to account for the observed rate of water loss. Further people at the same ET* value would be expected to have the same thermal sensation as demonstrated by Gonzalez [12].

\section{Humidity}

Though the temperature boundaries of the comfort zone are well defined and supported by laboratory and field observations, the humidity limits are less certain particularly at upper humidity levels. The physiological and energy balance considerations that led to ET* would indicate there is neither an upper or lower humidity limit in terms of thermal sensation. But laboratory, field and personal experiences suggest that there are humidity limits for comfort and acceptability.

Other aspects of humidity discomfort may not be energy related. The perception of skin moisture and the interactions of clothing fabrics with the skin may be due to the moisture itself. The skin's outer layer of dead squamous cells of the stratum cornium can readily absorb or lose water. With moisture addition, the cells swell and soften. With drying, they shrink and become hard. In this setting the skin's moisture may be better indicated or characterized by the relative humidity of the skin (RHsk) rather than skin wettedness [13]. 


$$
R H s k=P m / P s, s k
$$

where $\mathrm{Pm}$ is the average vapor pressure of the skin and $P s, s k$ is the saturated vapor pressure of water at the skin temperature. Typically, the water content of the stratum cornium is about $10 \%$ but it can absorb much more, up to about 4 times its dry weight [14].

Skin moisture may be detected by mechanoreceptors of the skin and hair follicles or some other neural mechanism that senses the skin's swelling and shrinking. At high levels of skin moisture the swelling is sufficient to close or reduce the lumen of sweat glands and reduce sweating as in hidromeiosis [15]. Hidromeiosis occurs at RHsk $>0.9$. Conversely, under good drying conditions the skin can shrink to the extent that lesions form.

As mentioned previously, the other term for characterizing skin moisture is skin wettedness $(w)$ or the size of the water film as a fraction of total skin area that is necessary to account for the observed evaporative heat loss from the skin (Esk).

$$
E s k=w A d u h e(P s, s k-P a)
$$

where Adu is total skin area, he is evaporative heat transfer coefficient and $\mathrm{Pa}$ is the ambient vapor pressure. Skin wettedness correlates well with warm discomfort(16) and people rarely report feeling comfortable at skin wettedness levels near or above $25 \%$. With intense sweating, sweat normally begins to drip from some surfaces when the average skin wettedness for the whole body is about $80 \%$ (17).

Skin wettedness and skin relative humidity are related.

$$
R H s k=w+(1-w) P a / P s, s k
$$

From equation 4 it is clear that $R H s k$ will be greater than $w$ except for $w=1$. It is also evident that with a constant $w$, RHsk increases with ambient humidity $(\mathrm{Pa})$. Thus, though the $\mathrm{ET}^{*}$ temperature boundaries have constant skin wettedness levels, the RHsk of the skin increases with increasing ambient humidity and results in swelling and softening.

Humans are sensitive to moisture and can consistently describe the humidity of the environment using word scales as is demonstrated in Figure 2 [18]. The points in the figure are the average of 20 sedentary subjects. The subject's humidity judgments appear to be functions of the air's dew point, a measure of absolute humidity, and are relatively unaffected by the ambient temperature. Further, people are also good at perceiving skin moisture as illustrated in

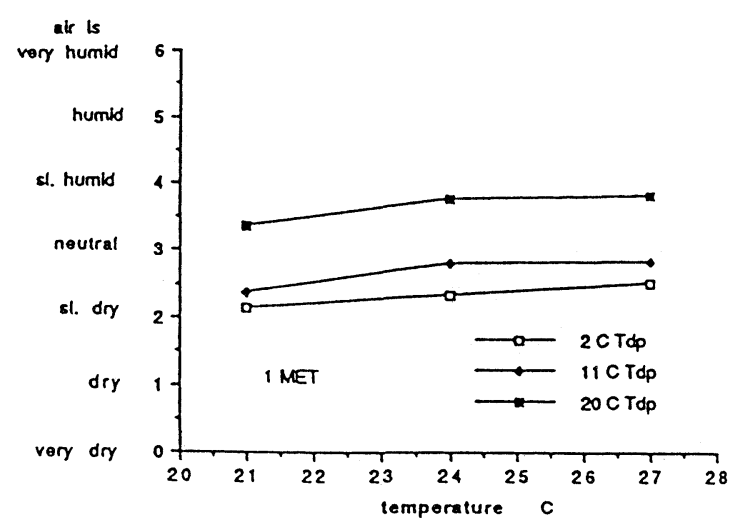

Figure 2. Perceived ambient humidity by sedentary subjects.

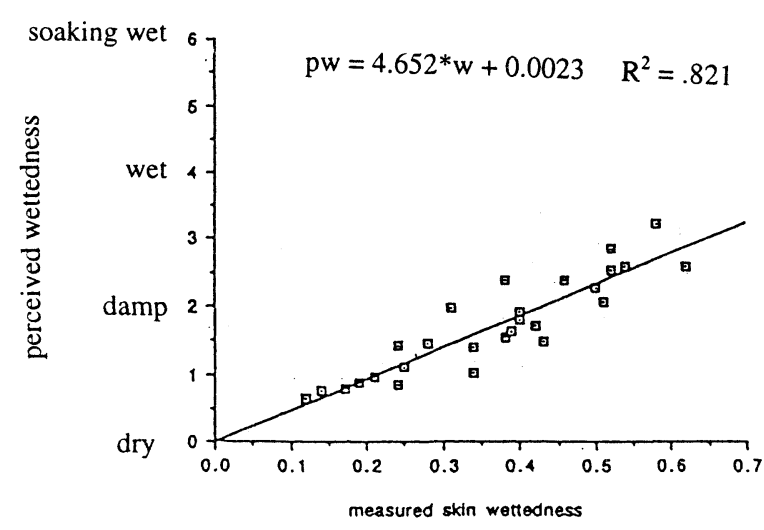

Figure 3. Perceived skin moisture correlated to measured skin wettedness. 
Figure 3 where perceived skin wettedness is seen to correlate well with measured skin wettedness. Each point is the average of five subjects.

In situations of prolonged sweating, skin wettedness slowly increases with time because of accumulating salt on the skin. The increasing salt occurs because the water in perspiration evaporates while the dissolved materials, principally sodium chloride, remain on the surface. The salt lowers the vapor pressure of the sweat film decreasing its rate of evaporation per unit area. The area of the film then naturally increases in order that evaporation will equal the rate of sweat secretion[19]. It is thought that part of the relief and pleasure that bathing brings after a warm day or strenuous activity is that by cleaning the skin, perspiration can evaporate more efficiently with reduced skin wettedness.

Clothing can be one of the detractors from acceptability in humid environments. Measurements by Gwosdow [20] reveal that the friction between skin and clothing increases abruptly above skin wettedness levels of $25 \%$ (Figure 4). Further, fabrics are perceived to be rougher or to have a coarser texture and to be less pleasant with increasing skin moisture(Figure 5). This may be one of the reasons, that in the comfort studies cited earlier (16), the people have rarely indicated they were comfortable when they had skin wettedness levels near and above $25 \%$.

Following the reasoning above, the stickiness and perceived fabric coarseness and unpleasantness with humidity and skin moisture could affect merchandising. Fabrics, clothing, textures and the like will be more pleasant and could sell more readily in a dry environment than in a humid warm one.

\section{Low Humidity}

Low humidity affects comfort and health. Comfort complaints about dry nose,

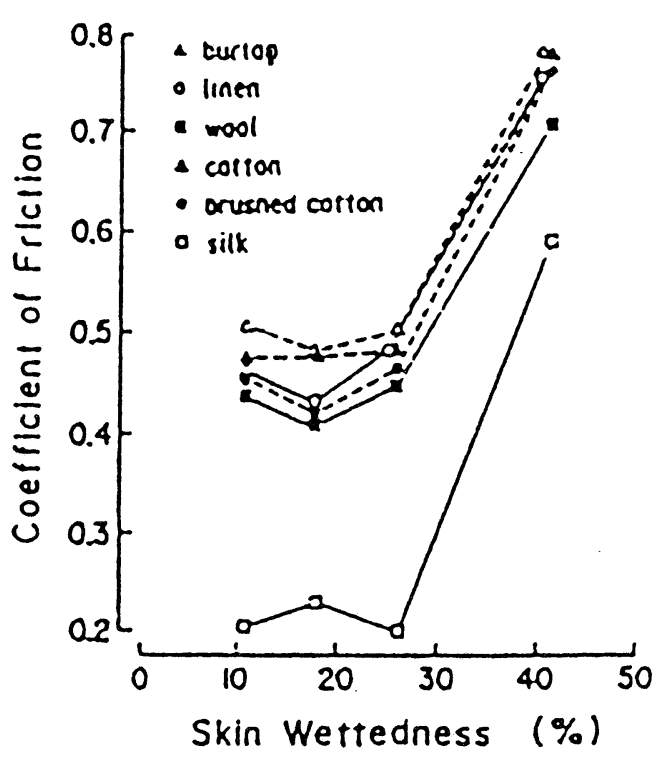

Figure 4. Coefficient of friction between fabrics and the skin of the forearm in terms of skin moisture measured adjacent to the test site.

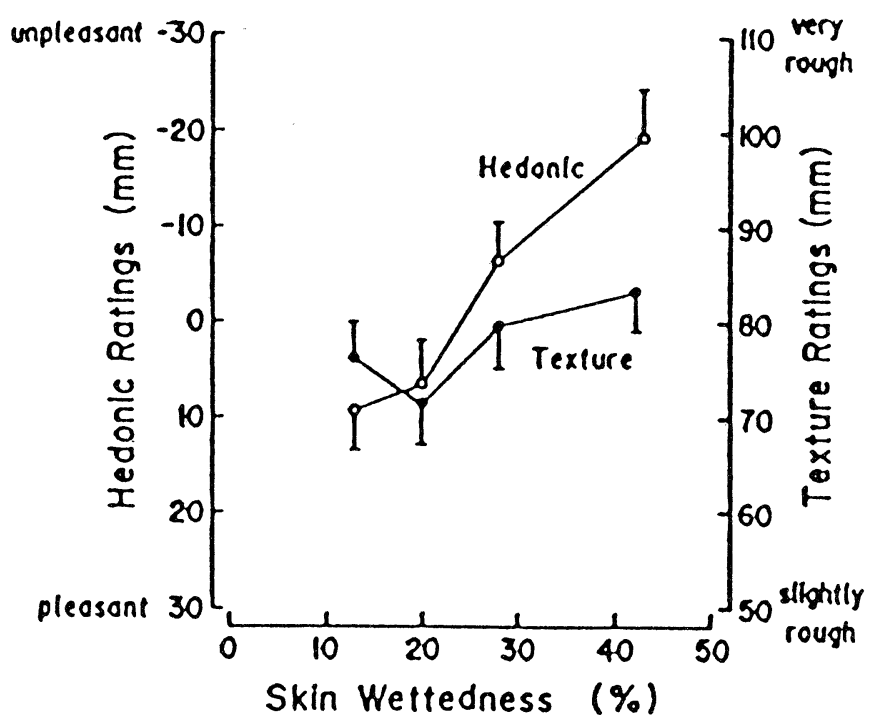

Figure 5. Texture and pleasantness ratings for textiles in Figure 4. Ratings were made during the friction measurements. The ratings were made by marking line scales. Responses (distance $(\mathrm{mm})$ from scale zero point) are the average of all fabrics at same test condition. 
throat, eyes and skin occur in low humidity conditions, typically when the dew point is less than $0^{\circ} \mathrm{C}$. Low humidity can lead to drying of the skin and mucous surfaces. On respiratory surfaces, drying can concentrate mucous to the extent that ciliary clearance and phagocytic activities are reduced increasing susceptibility to respiratory disease as well as discomfort. Green [21] quantified that respiratory illness and absenteeism increase in winter with decreasing humidity. He found that any increase in humidity from the low winter levels decreased absenteeism.

Excessive drying of the skin can lead to lesions, skin roughness, discomfort, and impair the skin's protective functions. Dusty environments, particularly if the dust is hygroscopic, can further exacerbate low humidity dry skin conditions [22].

To decrease the possibility of discomfort due to low humidity the current ASHRAE Standard 55 specifies that the dew point temperature in occupied spaces should not be less than $3^{\circ} \mathrm{C}$. Adherence to this standard should prevent eye discomfort which has been observed to increase with time in low humidity environments ( $\mathrm{Tdp}<2{ }^{\circ} \mathrm{C}$, Liviana et al. [23]).

\section{High Humidity}

Comfort is reduced by elevated humidity levels. At lower levels of humidity, thermal sensation is a good indicator of overall thermal comfort and acceptability, but at high humidity levels Tanabe [24] found that thermal sensation alone is not a reliable predictor of thermal comfort. Nevins [25] recommended that on the warm side of the comfort zone the relative humidity not exceed $60 \%$ to prevent warm discomfort.

That the upper limit of the comfort zone is controversial and not clearly defined is evidenced by the evolution of ASHRAE Standard 55 from 1974 to the present (Figure 7). The upper humidity limit was a dew point of $17^{\circ} \mathrm{C}$ in the 1974 and 1981 standards, based not so much on comfort as on considerations of mold growth and other moisture related phenomena. In the 1992 edition, Standard 55 specified $60 \%$ relative humidity as the upper limit also based primarily on considerations of mold growth. This limit was challenged for not being based on direct human thermal comfort and for being too restrictive for evaporative coolers. These air coolers are cost and energy efficient and popular in the hot dry south western part of the US. In 1994, Addendum 55a [26] was approved with upper humidity limits of 18 and $20^{\circ} \mathrm{C}$ wet bulb

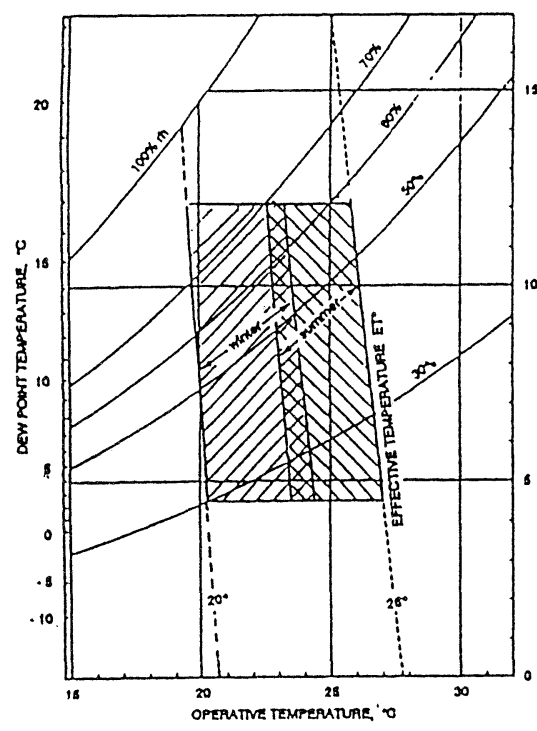

1981

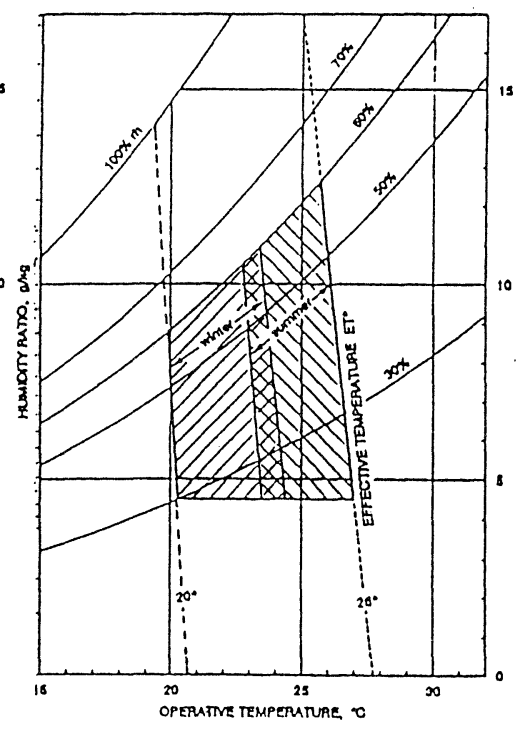

1992

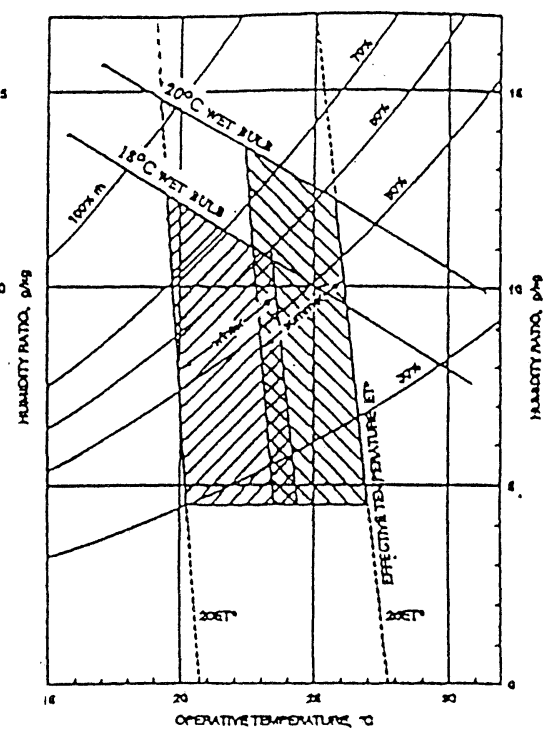

1994

Figure 7. Comfort zones of ASHRAE standard 55 from 1981 to present. 
temperatures for the winter and summer comfort zones respectively. Though based on limited comfort data, Addendum 55a is less restrictive to evaporative coolers.

The overall satisfaction an occupant has with the thermal environment is probably a cognitive result of temperature, moisture, friction and other sensations. A recent comfort study [18] done at temperatures of 21 to $27^{\circ} \mathrm{C}$ with dew points of 2 to $20^{\circ} \mathrm{C}$ with the subjects at three levels of activity (sedentary, intermittent walking and standing, and continuous walking) give extensive subjective responses of 20 subjects and measured physiological responses from 5 subjects. The subjective ratings include thermal sensation, perceived skin wettedness, thermal acceptability and others. For thermal acceptability the participants indicated if the environment was thermally acceptable or not with the instructions that an unacceptable condition would be sufficient to evoke a behavioral action to improve the climate and/ or reduce discomfort, e.g., open a window, turn on a fan, change the thermostat setting, alter clothing, complain, or leave.

The thermal acceptability (TAC) responses for humidities greater than $50 \%$ from that study correlated strongly with absolute humidity or humidity ratio and temperature $\left(\mathrm{r}^{\wedge} 2=.96\right)[27]$. Loci for $\mathrm{TAC}=60$, 70,80 and $90 \%$ are shown on the psychrometric chart of Figure 8.

The thermal acceptability loci shift with Ta is as expected but now the subtle effect of humidity can also be clearly seen. Superimposed on the acceptability loci of Figure 8 are the outlines of a psychrometric chart and the boundaries of the 1994 summer comfort zone of Addendum 55a (dark lines) from Figure 7. The shape of upper humidity limit of Addendum 55a is the 20 wet bulb line (WB) and this limit conforms reasonably well with the TAC loci. However, compliance of this particular data set with the zone's $80 \%$ thermal acceptability requirement would be improved if the zone were shifted slightly (about $1.5^{\circ} \mathrm{C}$ ) to cooler temperatures (dashed lines).

\section{Perceived Air Quality}

Humidity also affects our perceptions of air quality and that aspect of comfort and satisfaction with the environment. Odors can detract from the acceptability of an environment and humidity may stimulate or hinder odor sources and olfactory sensations [28] but in addition, our judgments about the perceived air quality appear be influenced by physical factors of temperature, humidity and air motion. Cooler drier air is somehow perceived as being freer of contaminants. Even in a clean non odorous and well ventilated space, the perceived freshness of the air decreases with increasing humidity and temperature. Figure 9 shows the subjects' judgments of air freshness upon entering a test room [18]. The odorless room was well

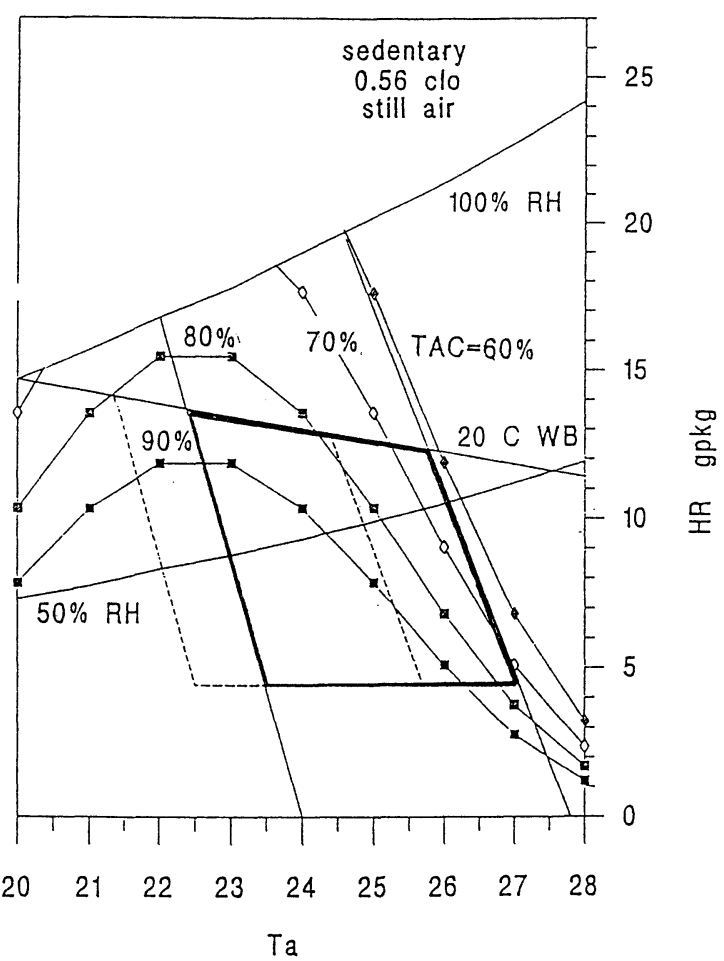

Figure 8. Thermal acceptability (TAC) loci in terms of environmental temperature (Ta) and humidity ratio (HR) for sedentary persons in clothing of 0.56 clo after one hour in still air. 
ventilated with $15 \mathrm{~L} / \mathrm{s}$ per person of clean air. The responses indicate that humidity made the subjects feel the air was less fresh. Since a person's olfactory system adapts to odor in a short time, the lack of a transient component to air freshness in Figure 9 implies the chamber air was odorless.

High occupant acceptance of a space's thermal environment and air quality is very important from a designer's or operator's point of view. For this laboratory study, the subjects judged whether the air quality was acceptable or not, under the instructions that an unacceptable condition would evoke a behavioral action to improve the environment and/or reduce discomfort, e.g., open a window, turn on a fan, change the thermostat setting, alter clothing, complain, or leave. The acceptability of the perceived air quality

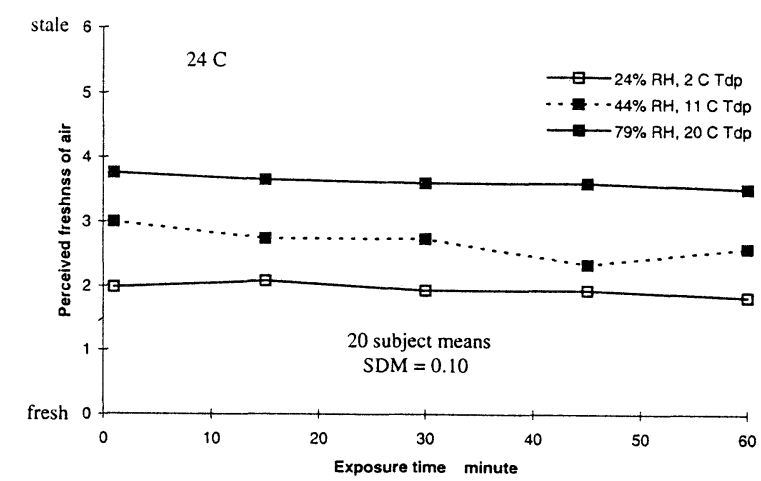

Figure 9. Transient perceptions of the air's freshness from sedentary persons after entering a test chamber.

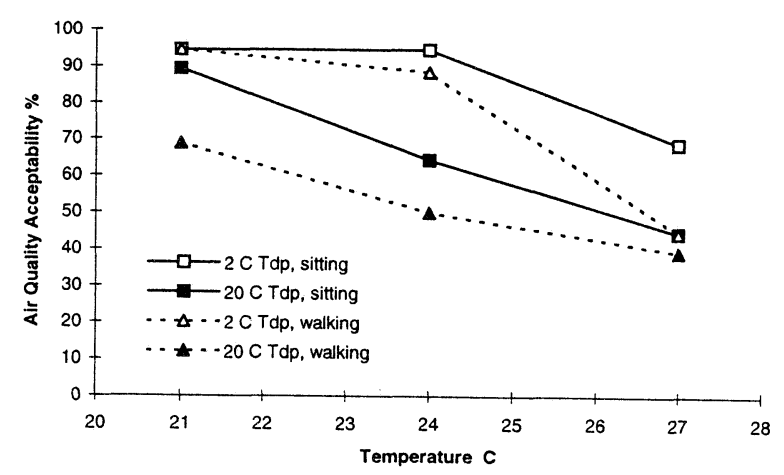

Figure 10. Occupant acceptance of perceived air quality of clean air in a well ventilated space.
(Figure 10) was affected strongly by humidity in this clean air environment. The $20^{\circ} \mathrm{C}$ dew point ( $\mathrm{Tdp}$ ) condition ( $\mathrm{RH}>65 \%$ ) was particularly associated with the perception of unacceptable air quality.

Recently, Fang et al. [29] at the Technical University of Denmark has found similar results for both clean air and air contaminated with emissions for common building materials. That is, for a particular pollution condition the air quality was perceived to be more acceptable with decreasing temperature and or humidity. The acceptability correlates strongly with enthalpy. Further, the study found that temperature and humidity had minimal or no effect on the emission rate of the materials tested.

\section{Conclusion}

Humidity affects comfort in a number of ways both directly and indirectly. At a given temperature, decreased humidity results in occupants feeling cooler, drier and to a point more comfortable; further fabrics feel smoother and more pleasant and the air is perceived to be fresher, less stale and more acceptable. For the sedentary person, a $30 \%$ change in relative humidity has the same effect on thermal balance and thermal sensation as a $1 \mathrm{C}$ change in temperature.

In warm conditions thermal discomfort increases with humidity. The discomfort appears linked with skin moisture, as persons rarely judge themselves comfortable in situation where skin wettedness is above $25 \%$. The discomfort associated with skin moisture could in part be due to friction between skin and clothing. When fabrics ranging from rough burlap to wool, cotton, polyester, and smooth silk are pulled across the skin, the measured pull force increases with humidity and perspiration as does the fabrics perceived texture or roughness.

Much of the discomfort related to higher 
humidities appears to be due the higher levels of skin moisture, thus increased air speed alone is often effective in such environments. Further, the comfort and related benefits perceived by occupants and customers from humidity reduction may encourage and justify the design and implementation of HVAC systems with increased dehumidification capabilities such as Cold Air/Ice Storage systems [30].

The effect of humidity on thermal balance and in turn skin temperature and thermal sensation has a clear mechanism. But other effects of humidity on human sensation and health have less clear mechanisms and could benefit from further study.

\section{References}

[1] ASHRAE standard 55-66: "Thermal Environmental Conditions for Human Occupancy." American Society of Heating Refrigeration and Air-Conditioning Engineers, Atlanta, 1966.

[2] Hardy,J.D.; Stolwijk,J.A.J.; and Gagge,A.P.; "Man." In: Comparative Physiology of Thermoregulation, Chapter 5, Charles C. Thomas, Springfield, Ill., 1971 .

[3] Chatonnet,J.; and Cabanac,M.;"The perception of thermal comfort." Int. J. Biometeorology, 9, pp.183-193, 1965.

[4] Kuno,S.; Ohno,H.; and Nakahara,N.;"A two dimensional model expressing thermal sensation in transitional conditions." ASHRAE Trans., Vol.93,Pt.2,1987,pp.396406.

[5] Gagge,A.P.;"Introduction to thermal comfort." Les Editions de l'INSERM, INSERM 75,pp.11-24, 1977.

[6] Gagge,A.P.; Stolwijk,J.; and Nishi,Y.;"An effective temperature scale based on a simple model of human physiological regulatory response," ASHRAE Trans., Vol.77, Pt.1, 1971, pp.247-262.

[7] Fanger,P.O.; Thermal Comfort,1972, McGraw-Hill, New York.

[8] ASHRAE;"ANSI/ASHRAE Standard 55-
1992, Thermal Conditions for Human Occupancy." 1992, American Society of Heating Refrigeration and Air-Conditioning Engineers, Atlanta.

[9]Fishman,D.S.;and Pimbert,S.L.;"Survey of subjective responses to the thermal environment in offices." Indoor Climate, 1979, Danish Building Research Institute, Copenhagen.

[10] Gagge,A.P.; and Nevins,R.G.; Effect of Energy Conservation Guidelines on Comfort, Acceptability and Health. Final Report of Contract \# CO-04-51891-00 of Federal Energy Administration,1976.

[11] Gagge,A.P.;"A new physiological variable associated with sensible and insensible perspiration." American Journal of Physiology, Vol.20(2), 1937, pp.277-287.

[12] Gonzalez,R.R.; Berglund,L.; and Gagge,A.P.;"Indices of thermoregulatory strain for moderate exercise in the heat." Journal of Applied Physiology: Respiration Environment Exercise Physiology, 446,1978,pp.889-899.

[13] Mole,R.H.; "The relative humidity of the skin." Journal. Physiology., London, Vol.107, 1948, pp.399-411.

[14] Odland, G.F. , 1970, The Skin , Washington School of Medicine, St. Louis.

[15] Kerslake,D.McK.; The Stress of Hot Environments,1972, University Press, Cambridge.

[16] Berglund,L.G.; and Cunningham,D.J. ;"Parameters of human discomfort in warm environments." ASHRAE Trans., Vol.92, Pt.2,1986,pp.732-746.

[17] Berglund,L.G.; and Gonzalez,R.R; Evaporation of sweat from sedentary human in humid environments. Journal of Applied Physiology: Respirat. Environ. Exercise Phyiol., Vol 42, 1977, pp 767-772.

[18] Berglund, L.G.; and W.S. Cain. 1989. Perceived air quality and the thermal environment. In: The Human Equation: Health and Comfort. Proceedings of ASHRAE/SOEH Conference IAQ'89. ASHRAE, A tlanta, pp. 93-99.

[19] Berglund,L.G.; and McNall,P.E.; Human 
sweat film and composition during prolonged sweating. Journal of Applied Physiology, Vol. 35, 1973, pp. 714-718.

[20] Gwosdow,A.R.; Stevens,J.C.; Berglund,L.; and Stolwijk,J.A.J.; "Skin friction and fabric sensations in neutral and warm environments." Textile Research Journal,Vol.56,1986, pp.574-580.

[21] Green,G.H.;"Positive and negative effects of building humidification." ASHRAE Trans, Vol.88, pt.1,1982,pp.1049-1061.

[22] White,I.R.; and Rycroft,R.J.G.;"Low humidity occupational dermatosis." Contact Dermatology,Vol.8, 1982, pp.287-290.

[23] Liviana,J.E.; Rohles,F.H.; and Bullock,O.D.;"Humidity, comfort and contact lenses." ASHRAE Trans., Vol.94, Pt.1, 1988, pp.3-11.

[24] Tanabe,S.; Kimura,K.; and Hara,T.; "Thermal comfort requirements during the summer season in Japan," ASHRAE Trans.,Vol.93,Pt.1,1987,pp.564 -577.

[25] Nevins,R.; Gonzalez,R.R.; Nishi,Y.; and Gagge,A.P.;"Effect of changes in ambient temperature and level of humidity on comfort and thermal sensations." ASHRAE Trans., Vol.81, Pt.2, 1975.

[26] ASHRAE; "ANSI/ASHRAE Standard 55-1992, Addendum 55a." 1994, American Society of Heating Refrigeration and AirConditioning Engineers, Atlanta.

[27] Berglund,L.G.; "Comfort CriteriaHumidity and Standards." Proc of Pan Pacific Symposium on Buildings and Urban Environment Conditioning in Asia,Vol. 2,pp. 369-382.Dept. of Architecture, Faculty of Engineering, Nagoya University, Nagoya, Japan, 1995.

[28] Kerka, W.F. and Humphreys, C.M., 1956. Temperature and humidity effect on odour perception. ASHRAE Transactions 62, pp. 531-552.

[29] Fang,L., Clausen,G. and Fanger, P.O., 1996. The Impact of Temperature and Humidity on Perception and Emissions of Indoor Air Pollutants. Indoor Air'96. Vol. 4:349-354. Institute of Public Health, Tokyo. [30] Kirkpatrick,A.T.Thermal and on-thermal effects of humidity on comfort 